\title{
Maker of Patterns
}

Steven J. Miller

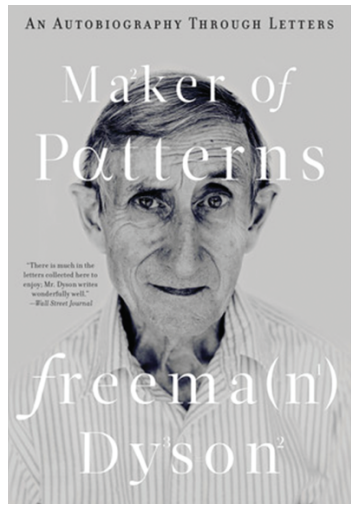

Maker of Patterns (An Autobiography Through Letters) By Freeman Dyson (Liveright, 2018, 416 pages).

Through voluminous correspondence with his family in England, in this book the mathematical physicist Freeman Dyson gives us an entertaining story of physics and physicists from the perspectives of someone whose work was at the forefront of so many subjects. It is perspectives and not perspective, as we are treated to his thoughts from when the events happened, as well as commentary written for this book where he has the benefit of the passage of time. Very few technical details are given on his professional work, but for the purposes of the book very little detail is needed. While those with expertise in his areas will know the backstory behind the theories hinted at in his letters, the purpose of this book is not to expound on those. Rather, it is to discuss the life lessons and observations from someone who has significantly contributed in a variety of fields over sixty years. The book is filled with rich, insightful commentary on many issues; as this is a review for a mathematical audience, below I will mostly concentrate on some valuable professional lessons one can gain from his experiences.

To set the stage: Freeman Dyson is one of the giants of 20th century science, famous for his theories and advocacy on many social issues. Born in England in 1923, he studied

Steven J. Miller is a professor of mathematics at Williams College and is currently on sabbatical at Carnegie Mellon University. His email address is sjm1@wi 11iams. edu.

Communicated by Notices Book Review Editor Stephan Ramon Garcia.

For permission to reprint this article, please contact: reprint -permission@ams.org.

DOI: https://dx.doi.org/10.1090/noti 1874 with many of the greats at Cambridge in the early 1940s before joining the British war effort in the Operational Research Section of the RAF Bomber Command. After the war, in 1947 he travelled to America under a Commonwealth Scholarship to study with Bethe at Cornell, meeting, among others, Richard Feynman, whose perspective on quantum electrodynamics he helped explain and develop. After a year at the Institute for Advanced Study, he returned to England, working at the University of Birmingham until 1951 when he joined the faculty at Cornell. He moved back to IAS permanently in 1953, where he is now an emeritus professor.

In over six decades of scientific study he has made contributions in varied fields such as quantum electrodynamics, Diophantine approximation, and random matrix theory. Though numerous concepts bear his name, from the Dyson crank (which emerges in the study of modular forms and partition problems) to the Dyson sphere (a staggering engineering feat where one builds a shell completely enveloping a star, allowing one to harness its energy and provide almost limitless area for habitation), this book on the Maker of Patterns is not about the technical details of his contributions. Instead, it is a collection of letters written by Dyson, mostly to his parents, with commentary from him looking back at those earlier moments in his life. We are thus treated to a personal account of some of the most pivotal moments of the last century, from the horrors of World War II and the reconciliations afterwards to the development and acceptance of new theories of physics to efforts by scientists concerned about nuclear war to preserve the peace and the ethical issues of biological research.

The letters cover his life from the start of his student days at Cambridge to the late 1970s. We read his views on everything from family to politics, both with the immediacy of someone living it as well as the perspective in the commentaries that comes from years of experience. As the book is almost 400 pages, for the purposes of this review most of the passages chosen below highlight not just big moments, but more importantly good advice on how to 
be a successful and happy scientist. Though such a focus omits the details of his science and peace advocacy, as well as his personal life, doing so keeps this review to a readable length, and these observations deserve a wide audience.

Below are several gems grouped by content, and not chronology. Many of the excerpts are deliberately taken from 1948 as he was reconciling the works of Schwinger and Feynman, and this coherent collection gives the reader a sense of what is in this book. Feynman and Schwinger shared the 1965 Nobel Prize in Physics with Sin-Itiro Tomonaga for their work building theories of quantum electrodynamics. The last is from an exciting time in mathematical physics, when random matrix theory was being recognized as a useful tool for nuclear physics; sadly there are no letters describing his famous 'chance encounter' with Hugh Montgomery, where the connections to number theory (through the Riemann zeta function) were first noticed.

The first set of excerpts concern the new theories by Schwinger and Feynman on quantum electrodynamics. We are transported back to this exciting time as new ideas are being proposed, tested, adapted, and then adopted. Dyson becomes the person in the right place at the right time with the right training. These letters provide a wonderful commentary on the emergence of a new perspective, and how the establishment reacts.

January 24, 1948: A new period in physics started with the Columbia University experiments last summer which for the first time contradicted the existing quantum theory outside the nucleus. The first step was taken by Bethe when he showed how the theory could be extended to explain the Columbia results. My calculations of last term were part of the detailed carrying out of this extension. Then there was another big step in November when Julian Schwinger at Cambridge, Mass., produced a formally unified theory including Bethe's work and covering the whole of nonnuclear physics.

September 14, 1948: On the third day of the journey a remarkable thing happened; going into a sort of semistupor as one does after forty-eight hours of bus riding, I began to think very hard about physics, and particularly about the rival radiation theories of Schwinger and Feynman. Gradually my thoughts grew more coherent, and before I knew where I was, I had solved the problem that had been in the back of my mind all this year, which was to prove the equivalence of the two theories. Moreover, since each of the two theories is superior in certain features, the proof of equivalence furnished a new form of the Schwinger theory which combines the advantages of both.
September 30, 1948: To arrive at the frontiers of physics is like breaking through a crust, after which one finds plenty of room to move in a lot of directions. .... One thing which I must always keep in mind to prevent me from getting too conceited is that I was extraordinarily lucky over the piece of work I have just finished. The work consisted of a unification of radiation theory, combining the advantageous features of the two theories put forward by Schwinger and Feynman. It happened that I was the only young person in the world who had worked with the Schwinger theory from the beginning and had also had long personal contact with Feynman at Cornell, so I had a unique opportunity to put the two together. .... It is for the sake of opportunities like this that I want to spend five more years poor and free rather than as a wellpaid civil servant.

The final passage of this section is, for the expert, painfully brief. Freeman Dyson played a major role in the development of random matrix theory, which is able to accurately model phenomena ranging from the energy levels of heavy nuclei to zeros of $L$-functions. There are a few brief mentions to his collaboration with Mehta and others, but the purpose of this book is not to go into the details of what he studied and proved, and letters like this are but markers to what he has done.

May 25, 1961: You ask what I have been calculating so industriously for the last three months. I will try to explain what it is about. The idea is to work out a new kind of statistical theory which will apply to the dynamics of heavy nuclei.

The next set of excerpts give a wonderful view of what it is like to be a scientist. These range from a frank description of interactions with senior colleagues, to the joys of being absorbed in a problem and the challenges of finding time to work, to the creation of institutes. There are also personal recollections of how nervous one is when giving talks to audiences of experts, and the stresses and mental health issues people encounter in their careers. These latter are being recognized more and more, with institutions devoting significant resources to these problems. As a mathematician who has trained and mentored many postdocs, graduate students, and undergraduates, I found these passages especially impactful.

Commentary on the letter of October 17, 1948: The following letter to Oppenheimer contains some technical language which nonexpert readers should skip. Translated into plain language, the letter tells Oppenheimer to listen to what Feynman has to say and stop raising silly ob- 
jections. I disguised this message by wrapping it up in polite and diplomatic phrases.

November 14, 1948: Oppenheimer is in California this weekend, .... I have been observing his behavior rather carefully during seminars. If one is saying, for the benefit of the audience, things he knows already, he cannot resist hurrying one on to something else; when one says things that he doesn't know or immediately agree with, he breaks in before the point is fully established with acute and sometimes devastating criticisms, .... On Tuesday we had our fiercest public battle so far, .... He came down on me like a ton of bricks and conclusively won the argument as far as the public was concerned. However, afterwards he was very friendly to me and even apologized to me. When life is like this the great thing is to keep a sense of proportion, and avoid becoming a nervous wreck like Oppy. So far I think I'm succeeding, but you should not be surprised when I write melancholy letters occasionally.

May 1, 1949, Princeton: The Washington meeting lasted three days and was on the whole very successful. ... Being in the most fashionable branch of physics, I was put into the largest auditorium, a grandiose monstrosity with enormous gold-painted columns stretching up to a domed and bright blue roof. .... About half an hour before I was due to start, I came in and had a look around this place, and the sight of it made me so nervous that none of my previous agony at Chicago and elsewhere could faintly compare with it. For that last half-hour I was in a terrible state, sitting in a chair and sweating all over and feeling I could not even stand up.

October 25, 1952: Two days after the phone call from Oppy, I had a conversation with Bethe, and out of it I got a new idea for a major piece of research in physics. This has absorbed me completely during the last ten days. ... These last ten days have been great fun, but they make it even more clear how necessary it is to go to Princeton. I simply cannot go on at this pace. All my routine jobs are left undone and are piling up ahead of me.

November 1, 1952: My activities in the department are growing by leaps and bounds. I now am directing an empire of eight people who are working hard on the meson calculations which I started six weeks ago. It is amazing how things are humming. Everyone is happy, and they are getting interesting results. It is easy to run such a group once you have a suitable job for them to do. I am happy about it all. When I leave here, they will say "Look how he built the department up in two years" instead of "He didn't like it so he quit after two years." This makes a great difference.

Chapter 20 Introductory Commentary: Adventures of a Psychiatric Nurse. When I was appointed a professor at the Institute for Advanced Study, I used to say that my real job was to be a psychiatric nurse, giving consolation and comfort to the young members when they suffered from loneliness or depression. The visiting members were in a highly stressful situation, facing a year or two of complete freedom, with the expectation that they should do something brilliant. If they failed to perform, given this unique opportunity, there was a real danger of psychological collapse. In my time as a professor I lost three young people whom I had invited as members, one by suicide and two who ended up in mental institutions. I do not know how many I saved. I only know that the institute is a dangerous place for young people, and as a professor, I bore a heavy responsibility for their mental health. The letters are as usual arranged chronologically, beginning with family affairs and then telling stories of psychological disasters.

As much of the book concerns his personal life, it is worth including a few of these items. The next set of quotes is representative of his impressions of America and Americans.

January 2, 1948: The fact that they [Americans] are more alone in the world than average English people probably accounts for their great spontaneous friendliness. I had heard this friendliness attributed to the size of the country and to people's loneliness in space, but I think the loneliness in time is more important.

November 14, 1948: After I wrote to you from Boston, I had an unequalled opportunity of seeing the real Boston,.... Boston is the most European of American cities, superficially reminiscent of London. Even the slums are old and built of brick, in contrast to the typical American slums which are built of wood and corrugated iron.

April 4, 1948: The revolutionary thing about the atomic bomb is not that it is so lethal but that it is so cheap. ... The upshot of this is that 
when two powers both have even moderate quantities of plutonium at their disposal, to have the greater quantity is not a decisive advantage. The decisive factor in military strength is vulnerability. And the United States is likely to remain enormously more vulnerable to this sort of attack than Russia (let alone Western Europe). Hence in the course of time, and especially if Russia starts building a navy, there will be increasing pressure upon the United States to strike first before it is too late. As you say, it is very like 1914. I am an optimist too, but only in the very long run.

This last passage is from one of the final sections of the book. It and the letters that follow, which describe his interactions with others on the committee, give some sense of the challenges and importance of such work.

January 29, 1977: Today I went to the first meeting of a citizens' committee which is supposed to decide for the town of Princeton whether the biologists at the university are to be permitted to work with recombinant DNA. I was asked to serve on the committee and agreed to do so because this is an important question and I should not stand aside. The committee will involve a great deal of work, and is supposed to produce a final report by May 1 . We were told to expect to put into it about ten hours of work per week for ten weeks. It will probably add up to more than that.
For those looking for a technical description of some of the many areas where Dyson contributed, this is not the book to read. The most we get are the faintest outlines of subjects, with the barest mention of the issues. What we do get, and get well, are the thoughts and reflections of a major player from those times. We relive these times through letters written to non-experts, and thus the emphasis cannot be on the details, but rather on the people involved. This ranges from their personalities to how he interacted with them. There are many lessons here that transcend field and time, and are as relevant to the researchers of today as they were to those from 60 years ago. Thus, the lack of detail in the end gives the book more universality; the messages here can (and should) be read and understood by a wide audience. 